\title{
Biocides in wastewater treatment plants: mass balance analysis and pollution load estimation
}

\author{
Wang-Rong Liu ${ }^{\text {a,b }}$, Yuan-Yuan Yang ${ }^{\text {, }}$, You-Sheng Liu ${ }^{\text {a }}$, Li-Juan Zhang ${ }^{\mathrm{b}}$, Jian-Liang Zhao ${ }^{\mathrm{a}}$, \\ Qian-Qian Zhang ${ }^{\text {a }}$, Min Zhang ${ }^{\text {a }}$, Jin-Na Zhang ${ }^{\text {a }}$, Yu-Xia Jiang ${ }^{\text {a }}$, Guang-Guo Ying ${ }^{\text {a* }}$ \\ ${ }^{a}$ State Key Laboratory of Organic Geochemistry, Guangzhou Institute of Geochemistry, Chinese \\ Academy of Sciences, Guangzhou 510640, P R China
}

${ }^{\mathrm{b}}$ South China Institute of Environmental Sciences, Ministry of Environment Protection, Guangzhou 510655, P R China

* Corresponding author. Tel.:+86 020 85290200; fax: +86 02085290200.

E-mail address: guangguo.ying@gmail.com; or guang-guo.ying@gig.ac.cn (GG Ying).

\begin{abstract}
This study aimed to investigate the occurrence and removal of 19 biocides in ten different wastewater treatment plants (WWTPs), then estimate the usages and emissions per capita of 19 biocides based on mass balance analysis approach. The results showed that target biocides were universally detected in the WWTPs and their receiving rivers, and 19 for liquid samples and 18 for solid samples. The prominent compound for liquid was DEET (N, N-diethyl-3- methylbenzamide), with its maximum concentration of $393 \mathrm{ng} / \mathrm{L}$ in influent; while that for solid was triclocarban with its maximum concentration of $2.11 \times 10^{3} \mathrm{ng} / \mathrm{g}$ in anaerobic sludge. Most biocides were readily removed from the liquid phase of ten WWTPs, and the mean removal rate to $\sum 19$ biocides was up to $75 \%$. The removals
\end{abstract}


of target biocides were attributed to biodegradation and adsorption onto activated sludge. The mean input per capita for $\sum 19$ biocides based on influent was $907 \mu \mathrm{g} / \mathrm{d} /$ person, while the emissions per capita were $187 \mu \mathrm{g} / \mathrm{d} /$ person for effluent, and $121 \mu \mathrm{g} / \mathrm{d} /$ person for excess sludge. As demonstrated, the biocides contamination of the receiving rivers could pose potential ecological risks for aquatic organisms. Therefore, advanced wastewater treatment technologies should be developed to reduce the emission of biocides into the receiving environment.

Keywords: Biocides; Removal; Mass balance; Pollution load; Wastewater treatment plants.

\section{Introduction}

Biocides are defined as a class of active substances used for destroying or inhibiting any harmful organisms, but are harmless to human beings [1]. According to their usage pattern, they are classed into five categories: disinfectants, preservatives, pest control (e.g. insect repellents), and other biocidal products (e.g. antifouling agents) [1,2]. These chemicals are widely used at high dosage in various pharmaceuticals and personal care products (PPCPs) [3,4]. For example, parabens were used at various rinse-off products and leave-on products, with their highest concentrations on the order of $\mathrm{mg} / \mathrm{g}$ of the products including [5]. The azole fungicide climbazole is usually used in anti-dandruff shampoos, with the maximum content of $2.0 \%$ [6], while other fungicides (e.g., clotrimazole, ketoconazole and miconazole) are usually administered as ointment or oral anti-fungal medications, with the content range of 1 2\% in formulations [7]. In recent years, biocides have been frequently detected in the surface water and sediment $[8,9]$ and the biosolid-amended soils $[10,11]$, and the maximum concentration were up to the order of magnitude of $\mu \mathrm{g} / \mathrm{L}[12,13]$ and $\mu \mathrm{g} / \mathrm{g}$, dry weight (dw) 
$[14,15]$, respectively. The high concentration levels of biocides present in the receiving environment can cause some adverse effects to many organisms, and even human beings [16], such as general toxicity $[17,18]$, bioaccumulation $[19,20]$ and endocrine disrupting effects $[21,22]$. Therefore, it is essential to understand the removal of various biocides in wastewater treatment plants (WWTPs) and their emissions into the receiving environment.

According to some previous studies, municipal wastewater is regarded as the main emission source for biocides into the receiving environment $[9,23,24]$. After use of the products containing biocides, a mass of biocides were discharged into wastewater and then reached WWTPs through sewer network [25-27]. Therefore, various biocides were frequently detected in the influent and effluent of WWTPs [9, 25, 28], and their concentration levels in the sewage (sludge) of WWTPs varied among different process types and different regions, usually falling in the range from several tens to thousands ng/L (ng/g) [2, 29-31]. Generally, biocides cannot be removed completely by conventional treatment technologies, with removal rates ranging from $0 \%$ to almost $100 \%[9,26,30$, 32]. These previous reports mainly focus on a few or a class of biocides, or are limited in the investigation of only influent or effluent of a few WWTPs with same or similar treatment technologies. Currently, there is lack of a systematic investigation into the occurrence, removal, mass balance and pollution loads of different classes of biocides in WWTPs with different treatment technologies.

The aim of this study was to investigate the occurrence and removal of 19 target biocides in ten WWTPs of Guangdong province, South China. Further, mass balance analysis was applied to estimate their mass loads in the different process stages and to reveal their removal mechanisms. The usages and emissions of these biocides in the region were calculated based on their pollution loads in ten 
WWTPs. The results from this study can facilitate better understanding of the fate of various biocides in different WWTPs, and assess their elimination efficiencies in seven different wastewater treatment technologies. Moreover, the estimated pollution loads of biocides can provide much needed data to assess their potential ecological risks.

\section{Materials and methods}

\subsection{Chemicals}

The target compounds selected in this study were 19 common biocides, including: 8 fungicides, 2 insect repellents, 3 isothiazolinone antifouling agents, 4 preservatives and 2 disinfectants. The basic physico-chemical properties of these biocides are listed in Table S1 (Supplementary material), and their chemical structures are shown in Fig. S1. Eleven internal standards for the 19 target biocides were obtained from various suppliers. The supplier sources of all the chemicals and reagents are given in Text S1. Individual stock solutions of all target compounds and internal standards were prepared with methanol in amber glass bottles and kept at $-18{ }^{\circ} \mathrm{C}$.

\subsection{Sampling site and sample collection}

Ten WWTPs selected in this study are located in Guangzhou, Dongguan and Huizhou of Guangdong province, South China. The basic information of ten WWTPs is listed in Table 1. The treatment technologies applied in the WWTPs include $\mathrm{A}^{2} / \mathrm{O}$ (Anaerobic-Anoxic-Oxic), reversed $\mathrm{A}^{2} / \mathrm{O}$, modified A $2 / O$, modified A/O (Anaerobic-Oxic), MBR (Membrane Bio-Reactor), Carrousel 2000 Oxidation ditch and UNITANK (Combination alternating activated sludge process). The technical flow chart and the sampling points for each WWTP are shown in Fig. S2. Wastewater in each process stage, activated 
sludge in biochemical stages, return sludge and excess sludge were collected. It should be noted that the WWTPs received separated sewer system water. Meanwhile, the surface water and sediment in the receiving rivers were also collected from the upstream/downstream sites of $100 \mathrm{~m}$ far from the outlet of WWTPs.

Sampling campaigns were carried out during the period of May to October in 2015. All the samples for each WWTP were collected as $24 \mathrm{~h}$ flow integrated composite samples, while the surface water and sediment samples were grabbed once in the middle of the sampling day, and three replicates were obtained for each type of sample at each site. For each replication, the total volume of each sample was $1 \mathrm{~L}$ for water sample, approximately $1 \mathrm{~L}$ for the activated sludge and return sludge after filtering, and $0.5 \mathrm{~L}$ for the excess sludge and sediment. After sampling, the $\mathrm{pH}$ value of water sample was adjusted to 3.0 by $4 \mathrm{M} \mathrm{H}_{2} \mathrm{SO}_{4}$, then added with $5 \%$ methanol (v/v) to inhibit microbial growth. Sodium azide (1 $\mathrm{g} / \mathrm{L}$ each) was added into sludge/sediment sample to suppress potential microbial activity. Then, all the samples were placed in cool-boxes, transported to laboratory and stored in a $4{ }^{\circ} \mathrm{C}$ cold room before processing. The water samples were processed within $48 \mathrm{~h}$. The sediment samples were homogenized and passed through a $0.83 \mathrm{~mm}$ mesh after lyophilizing, then placed in glass bottles, and finally stored at $4{ }^{\circ} \mathrm{C}$ until the extraction.

In addition, basic quality parameters were measured for the influent, effluent and excess sludge samples of each WWTP and the surface water and sediment samples from receiving rivers. For the water samples, the $\mathrm{BOD}_{5}$ (biochemical oxygen demand for 5 days), $\mathrm{COD}$ (chemical oxygen demand), TP (total phosphorus), TN (total nitrogen ) and $\mathrm{NH}_{3}-\mathrm{N}$ (ammonia-nitrogen) were measured according to the reported methods [33]; their $\mathrm{pH}$, conductivity and DO (dissolved oxygen) were monitored on site by a YSI-Pro2030 multi-parameter water quality monitor (YSI Incorporated, USA). For sludge 
and sediment samples, TP, $\mathrm{TN}$ and $\mathrm{NH}_{3}-\mathrm{N}$ were determined similarly as water samples after digestion (TP and $\mathrm{TN}$ ) and $\mathrm{KCl}$ solution extraction $\left(\mathrm{NH}_{3}-\mathrm{N}\right)$, and the TOC (total organic carbon) was analyzed by a LiquiTOC analyzer (Elementar Analysensyteme Co., Germany). The results of water quality parameters and the removal rates of conventional pollution indicators are given in Table S2, and the sediment quality parameters in Table S3.

\subsection{Sample extraction and instrumental analysis}

Nineteen target biocides in wastewater, surface water, sludge and sediment samples were extracted and analyzed according to our previous method [2]. Briefly, water samples (1 L each) were filtered through $0.7 \mu \mathrm{m}$ glass fiber filters, and spiked with $100 \mathrm{ng}$ of an internal standard mixture $(100 \mu \mathrm{L}, 1$ mg/L each). Then, the samples were extracted by the solid phase extraction method using HLB cartridges (500 mg, $6 \mathrm{~mL}$ ), which were preconditioned consecutively with $10 \mathrm{~mL}$ methanol and $10 \mathrm{~mL}$ Milli-Q water before use. The target compounds were eluted from each cartridge with ethyl acetate three times ( $4 \mathrm{~mL}$ each). The final extracts were re-dissolved in $1 \mathrm{~mL}$ methanol prior to the instrumental analysis.

The extraction for sludge and sediment samples was performed using an ultrasonic extraction method. Briefly, each homogenized solid sample (1.0 g) was weighted accurately into a centrifuge tube $(30 \mathrm{~mL})$, followed by addition of $100 \mathrm{ng}$ of an internal standard mixture. Then, the samples were well mixed and then stored in a fridge overnight. On the second day, these samples were extracted each with $10 \mathrm{~mL}$ methanol by ultrasonication for $15 \mathrm{~min}$, followed by centrifugation for $10 \mathrm{~min}$ at the speed of $1402 \mathrm{~g}$. Then, each supernatant was transferred into a flat-bottomed flask ( $250 \mathrm{~mL})$ by a glass pipette. The extraction procedure was repeated twice using $10 \mathrm{~mL}$ methanol and then $5 \mathrm{~mL}$ methanol plus $5 \mathrm{~mL} 0.1 \%(\mathrm{v} / \mathrm{v})$ formic acid solution. After extraction, all the supernatants were combined and 
diluted to $300 \mathrm{~mL}$ with Milli-Q water. The mixed solutions were further purified using HLB cartridges (200 mg, $6 \mathrm{~mL}$ ) by the same procedure as the water samples.

The target compounds in the extracts were analyzed by an Agilent 1200 series ultrahigh-performance liquid chromatograph coupled to an Agilent 6460 triple quadrupole mass spectrometer with electrospray ionization under positive and negative ionization modes (UHPLC-ESI-MS-MS). The detailed operating conditions can be referred to our previous report [2]. The matrix effects during the process of sample analysis were reduced by addition of 11 internal standards before sample pre-treatment and by dilution of the extracts prior to instrumental analysis. The method recoveries, LOD (limit of detection) and LOQ (limit of quantification) for each target compound are given in Table S4. When the actual concentration is below the LOD or LOQ, LOQ/ 2 is used for calculation. Strict QA/QC (quality assurance and quality control) were performed during the analysis. In order to examine background contamination and instrument performance, a solvent blank, procedural blank and standard mixture $(100 \mu \mathrm{g} / \mathrm{L}$ each $)$ were included for every batch of samples, and all the target biocides were not detected in all blank samples.

\subsection{Mass balance and pollution load estimation}

Mass balance is an instructive approach to estimate the mass loads of a target compound entering and leaving a WWTP. The losses of the biocides into air are negligible since they have low volatilities. Thus, the mass balance equation can be obtained according to the previous report [34]:

MInfluent $=$ MEffluent + Msludge + MLoss

Where, Minfluent, MEffluent and Msludge (g/d) are the mass loads of a target biocide in the influent, effluent and excess sludge of each WWTP, respectively, and the estimation methods are detailed in Text S2; 
MLoss (g/d) stands for the loss mass loads of the target biocide during the whole treatment process, which is mainly caused by the total contribution of sorption and degradation in each process.

Based on the equation (1), the loss mass fractions (MfLoss \%) for each biocide was calculated according to the following equation:

MfLoss $\%=($ Minfluent - Meffluent - Msludge $) /$ Minfluent $\times 100 \%$

While the mass fractions in effluent (MfEffluent, \%) and excess sludge (Mfsludge, \%) were calculated by Meffluent/Minfluent \% and Msludge/Minfluent\%, respectively.

Moreover, the estimated pollution loads per capita of biocides in the influent/effluent/excess sludge for each WWTP could be calculated through the Minfluent/Effluent/sludge divided by the corresponding population served (Table 1). The back-estimated usage (U,t/y) and estimated emissions $(\mathrm{E}, \mathrm{t} / \mathrm{y})$ in Guangdong province or China were calculated by the following equations:

$\mathrm{U}=$ Linfluent $\times \mathrm{P}_{\text {Total }} \times 365.25 \times 10^{-12}$

$\mathrm{E}=\mathrm{E}_{\text {Rural }}+\mathrm{E}_{\mathrm{Urban}}=\left[\right.$ Linfluent $\times \mathrm{P}_{\text {Rural }}+($ LEffluent + LSludge $\left.) \times \mathrm{P}_{\text {Urban }}\right] \times 365.25 \times 10^{-12}$

Where, Linfluent, LEffluent and Lsludge ( $\mu \mathrm{g} / \mathrm{d} /$ person) are the estimated pollution load per capita of a target biocide in the influent, effluent and excess sludge (mean of ten WWTPs), respectively; $\mathrm{P}_{\text {Total }}, \mathrm{P}_{\text {Rural }}$ and $\mathrm{P}_{\mathrm{Urban}}$ are respectively the total population, rural population and urban population in Guangdong or China, the values are respectively 10724,3432 and $7292 \times 10^{4}$ persons for Guangdong, and 136782, 61866 and $74916 \times 10^{4}$ persons for China, which were obtained from the "China Statistical Yearbook" of 2015. For Equation (3), it was assumed that all biocides were used evenly across the territory of Guangdong and even China, and no sorption and transformation occurred during sewage transport to WWTPs; while equation (4) was based on the assumption of direct discharge of rural wastewater due to the absence of sewage treatment facilities. 


\section{Results}

\subsection{Concentrations of biocides in WWTPs and their receiving rivers}

\subsubsection{Concentrations of biocides in liquid phase}

Nineteen target biocides were all detected at least once in the sewage of different process stages from ten different WWTPs and their receiving waters. The concentration levels (range, mean, median and removal rate) for the detected biocides are summarized in Table S5, and the detailed concentrations in each WWTP and its receiving water are listed in Tables S6-S15. For the sewage from the different process stages ( $\mathrm{n} \geq 8$, Table S5), the biocides with the high mean concentrations were N, N-diethyl-3methylbenzamide (DEET, 119 393 ng/L), climbazole (114 268 ng/L), fluconazole (86.1 107 ng/L) and triclosan (61.6 312 ng/L). Methylparaben, ethylparaben and propylparaben occurred with high mean concentrations in influents and grit chambers (116 274 ng/L); but showed low mean concentrations $(2.25 \sim 36.8 \mathrm{ng} / \mathrm{L})$ in other process stages. In the receiving waters, the dominant biocides were DEET, 1,2-benzisothiazolinone (BIT), 2-n-octyl-4-isothiazolinone (OIT) and climbazole with mean concentrations of $235,193,195$ and $189 \mathrm{ng} / \mathrm{L}$, respectively.

For five classes of biocides, the concentration levels of $\sum 8$ fungicides and $\sum 4$ preservatives in influent (Fig. 1(a)) were obviously higher than other three classes of biocides, and their mean values were 593 and $655 \mathrm{ng} / \mathrm{L}$, respectively. The biocide categories with relatively high concentration levels in effluent (Fig. 1(b)) were fungicides, insect repellents and disinfectants (mean values: 94.4 260 ng/L), while antifoulings and preservatives occurred with low concentration levels (mean values: 5.46 and16.2 ng/L). In addition, the concentration distributions of $\sum 19$ biocides showed significant 
variations among ten WWTPs (Fig. S3). Some WWTPs such as HY, LJ and JX showed high levels of $\sum 19$ biocides, with values of 1.24 4.16, 0.43 3.24 and $0.48 \sim 3.59 \times 10^{3} \mathrm{ng} / \mathrm{L}$, while other WWTPs like XT and HJ had the relatively low concentrations of the 19 biocides ranging between 0.18 and 1.04 $\times 10^{3} \mathrm{ng} / \mathrm{L}$ (Fig. S3). The concentration variations were mainly attributed to the differences in the treatment technologies, population served, and sewage source among ten WWTPs.

\subsubsection{Concentrations of biocides in solid phase}

Table S16 summarizes the concentration levels (range, mean and median ) of the target biocides detected in the activated sludge/return sludge/excess sludge from ten different WWTPs and the sediment of their receiving rivers, and the detailed concentrations in each WWTP and corresponding sediment are displayed in Tables S17-S25. As listed in Table S16, eighteen biocides were detected in the sludge and sediment samples except for icaridin (not detected). The concentrations of most biocides in the sludge samples were obviously higher than those in the sediment samples, such as climbazole, miconazole, clotrimazole, ketoconazole, itraconazole, triclosan and triclocarban. The mean concentrations of these seven biocides in the sludge of main process stages ( $\mathrm{n} \geq 7$, Table $S 16$ ) were all more than $100 \mathrm{ng} / \mathrm{g}(\mathrm{dw})$. For miconazole, clotrimazole and triclosan, the mean concentrations in sludge varied from 562 to $869 \mathrm{ng} / \mathrm{g}$, while those for triclocarban were even up to $1.81 \sim 2.11 \times 10^{3} \mathrm{ng} / \mathrm{g}$. However, in the sediment of receiving rivers, much lower mean concentrations (3.87 44.4 ng/g) were found for these biocides, except for triclocarban (339 ng/g). For five classes of biocides in the excess sludge (Fig. 1(c)), the fungicides and disinfectants showed significantly higher concentration levels with the mean values of $1.63 \times 10^{3}$ and $2.57 \times 10^{3} \mathrm{ng} / \mathrm{g}$ than the other three classes of biocides (mean values: $4.24 \sim 43.8 \mathrm{ng} / \mathrm{g}$ ). Normally, the high levels of these biocides in the sludge and sediment are related to their high octanol-water partition coefficients $\left(\log K_{\text {ow }}\right)$ [35], which vary from 3.76 to 6.26 
(Table S1).

Additionally, the concentration distributions of the sum of eighteen detected biocides $\left(\sum 18\right.$ biocides) in the sludge samples are displayed in Fig. S4. The concentration of $\sum 18$ biocides almost remained stable in different process stages of the same WWTP, but the concentration levels between different process types of WWTPs presented some differences. For example, the concentrations of $\sum 18$ biocides in DTS-2, XT and HJ ranged from 2.00 to $4.00 \times 10^{3} \mathrm{ng} / \mathrm{g}$, while those for DTS- 1 and JX were up to $6.00 \sim 8.00 \times 10^{3} \mathrm{ng} / \mathrm{g}$, and others showed similar concentration levels $\left(4.00 \sim 6.00 \times 10^{3} \mathrm{ng} / \mathrm{g}\right)$ (Fig. S4). These differences were mainly linked to the concentrations and removal rate of biocides in liquid phase and the properties of activated sludge in different WWTPs.

\subsection{Removal efficiency in the liquid phase}

Incomplete removals of target biocides in the WWTPs were found, with the mean removal rates ranging from $-33 \%$ to $97 \%$ for individual biocides (Fig. 2(a)). All WWTPs, independent of their treatment technologies, exhibited excellent removal efficiencies for miconazole, clotrimazole, ketoconazole, itraconazole, icaridin, BIT, triclosan and four parabens, with their mean removal rates of more than $80 \%$. However, fluconazole and climbazole are exceptions, with very low mean removal rates of $-33 \%$ and $34 \%$, respectively. For five classes of biocides (Fig 2(b)), most WWTPs displayed similarly excellent removal efficiencies, especially for disinfectants, preservatives and antifoulings, with their mean removal rates of $80 \%, 95 \%$ and $86 \%$, respectively; while the insect repellents and fungicides showed relatively low removal rates $(62 \%$ and $48 \%)$.

Overall, ten different WWTPs exhibited high mean removal rates for conventional pollution indicators ( $\mathrm{BOD}_{5}, \mathrm{COD}, \mathrm{TN}, \mathrm{NH}_{3}-\mathrm{N}, \mathrm{TP}$ and TOC), in the range of 49\% 91\% (mean: 71\%) (Table S2), which showed good removal efficiency as reported in the literature [36]. Similarly, they also displayed 
high removal rates for $\sum 19$ biocides, ranging from $59 \%$ to $87 \%$ (Fig. S3). Among ten WWTPs, the removal rates for $\sum 19$ biocides in plants LJ, JX and HJ with modified A/O (Fig. S3(g)), MBR (Fig. S3(h)) and Carrousel 2000 oxidation ditch (Fig. S3(i)) were all above 80\%, which indicated that these technologies could remove target biocides better than the others. In term of different process stage, the removal rates (-36\% 71\%) for $\sum 19$ biocides demonstrated remarkable differences (Fig. S3), and more significant differences (-280\% 98\%) were observed for the five classes of biocides (Table S5). For the process stages of $n \geq 8$, the highest removal rates (mean) were occurred in anaerobic stage (13\%) for fungicides, anoxic stage (31\%) for insect repellents, anaerobic stage (37\%) for antifoulings, anoxic stage $(61 \%)$ for preservatives and grit chamber stage (28\%) for disinfectants (Table S5). For the process stages of $n \leq 2$, MBR and UNITANK revealed relatively good removal for the five classes of biocides, with the efficiency values of 30\% 66\% and 35\% 98\%, respectively (Table S5). In general, the biochemical stages made a significant contribution to the total removal of these biocides.

\subsection{Mass balance analysis}

Based on the principle of mass balance $($ Minfluent $=$ Meffluent + Msludge + MLoss $)$, the mass loads for input and output in ten WWTPs were estimated, and then the results for mass fractions are represented in Fig. 3. The distribution for the mass fractions displayed slight differences in different process types, but had three common patterns that could be summarized as follows: (1) the mass loads of fluconazole, climbazole and thiabendazole were mainly distributed in the effluent, and their loss parts were lower than those for the other biocides; (2) the mass fractions in excess sludge were mostly higher than $50 \%$ for miconaole, clotrimazole, itraconazole and triclocarban, which suggested that their removals from the liquid phase were transferred into the exccess sludge; and (3) the loss of mass fractions were over $50 \%$ for 9 biocides ( 2 insect repellents, 3 isothiazolinone antifouling agents and 4 parabens), and some 
were even close to $100 \%$, which indicated that most treatment technologies showed excellent removal efficiencies for these biocides, especially for the modified A/O (Fig. 3(g)), MBR (Fig. 3(h)), Carrousel 2000 oxidation ditch (Fig. 3(i)) and UNITANK (Fig. 3(j)). In addition, the mass fractions for some biocides showed negative values, which may be related to their lower concentrations in influent than in effluent (such as fluconazole and thiabendazole, see Table S5), or due to their strong adsorption in activated sludge and different sludge removal time (such as miconazole, clotrimazole, itraconazole and triclocarban). On the whole, a majority of biocides are easily to be adsorbed and degraded during the treatment process of different WWTPs, such as modified A/O, MBR, Carrousel 2000 oxidation ditch and UNITANK.

\subsection{Pollution loads estimation}

The pollution loads per capita for each target biocide in ten WWTPs are listed in Table 2. In influent, high pollution loads were found for the following compounds: DEET > ethylparaben > triclosan > methylparaben > climbazole, with the mean values of 151, 138, 132, 99.2 and $82.6 \mu \mathrm{g} / \mathrm{d} / \mathrm{person}$, respectively. In effluent, fluconazole, climbazole and DEET showed higher mean pollution loads ( $\geq 34.5 \mu \mathrm{g} / \mathrm{d} /$ person) than the others $(\leq 23.0 \mu \mathrm{g} / \mathrm{d} /$ person), which was related to the high concentration levels in influent but low removal rates for liquid phase (-33\% 62\%) (Fig.2(a)). In excess sludge, miconazole, clotrimazole, triclosan and triclocarban were the predominant compounds with mean pollution loads over $17.0 \mu \mathrm{g} / \mathrm{d} /$ person, and the others all less than $4.00 \mu \mathrm{g} / \mathrm{d} /$ person. Moreover, the mean input per capita for $\sum 19$ biocides based on influent was up to $907 \mu \mathrm{g} / \mathrm{d} /$ person; while the mean output per capita was up to $187 \mu \mathrm{g} / \mathrm{d} /$ person discharging into receiving rivers through effluent, and $121 \mu \mathrm{g} / \mathrm{d} /$ person remained in excess sludge. Thus, the biocides emissions from the effluent of WWTPs could cause the biocides pollution of receiving rivers, as shown in Fig. S5. 


\section{Discussion}

\subsection{Occurrence of biocides in WWTPs and their receiving rivers}

Nineteen target biocides were all detected in the water samples of ten Chinese WWTPs and their receiving rivers. Their concentration levels in the sewage of the WWTPs were in the median to high ng/L range, which were similar as those reported in the literatures $[9,30,36,37]$. For receiving waters, the pollution levels of these biocides were also consistent with other reports [13, 23, 32]. DEET and climbazole were the dominant biocides both in the WWTPs and receiving waters, which indicates that WWTPs effluent was an important source for those biocides in the riverine environment $[8,23]$. For some biocides, e.g. carbendazim, BIT and OIT, other pollution sources may exist, such as the emissions from industry and building [24, 38, 39]. Similarly, eighteen biocides were detected in the sludge of WWTPs and the sediment of their receiving rivers. Their concentration levels fell into the order of magnitude ng/g, except for triclocarban in sludge (up to $\mu \mathrm{g} / \mathrm{g}$ ), which are approximately equal to or lower than some previous reports $[8,29,31]$. On the whole, the target biocides commonly occurred in the WWTPs and their receiving rivers, and some of them showed relatively high concentration levels, such as DEET and climbazole for liquid samples and triclosan and triclocarban for solid samples.

\subsection{Removal mechanisms of biocides in WWTPs}

Most biocides could be removed significantly, with the mean removal rate for $\sum 19$ biocides up to $75 \%$ (Fig. 2(a)), and this was mainly attributed to the biochemical stages in WWTPs (Table S5). The removal efficiency of a chemical in WWTPs is closely related to adsorption and biodegradation in the 
activated sludge process [35], while the ability of adsorption and biodegradation depends on its physico-chemical property $[40,41]$. Based on the physico-chemical properties of the target biocides, their total estimated sludge adsorption rates (TESAR) and total estimated biodegradation rates (TEBR) in WWTPs can be calculated through EPI Suite model [42] as listed in Table S1. Thus, the total estimated removal rates (TERR) of biocides in WWTPs are equal to the sum of TESAR and TEBR. As shown in Fig. S6, the predicted TERR for most biocides are lower than the total measured removal rates (TMRR) in the present study, and the TERR are preponderantly contributed by the TESAR (1.77\% 92.2\%), while the TEBR are very low, ranging from $0.09 \%$ to $0.77 \%$, which indicates that the loss of target biocides in WWTPs was significantly caused by the adsorption of activated sludge. This was demonstrated by the distinguished adsorption ability of biocides to activated sludge based on the mass fractions and the estimated mass loads of biocides as the dissolved or adsorbed forms in the biochemical stages (Fig. 4). The high total mass loads for most biocides (miconazole, clotrimazole, ketoconazole, itraconazole, triclosan and triclocarban) were mainly contributed by the mass as the adsorbed form in the activated sludge, and their mass fractions were all closed to $100 \%$. These biocides have high organic carbon-base sorption coefficient $\left(\log K_{\mathrm{oc}}\right)$, with the values of 3.61 6.43 (Table $\mathrm{S} 1)$, thus easily adsorbed onto the activated sludge $[35,43]$. On the whole, the mass fractions of most biocides in the solid phase were greater than $50 \%$ (Fig. 4(a)), which indicates that these biocides removed in liquid phase had been transferred into the excess sludge instead of being really degraded or transformed (Table S16). In summary, most biocides are hard to be biodegraded, so it is necessary to develop more effective technologies for their removal, such as the advanced oxidation technologies [44-46]. 


\subsection{Environmental emissions and implications}

Based on the mean pollution loads per capita of every biocide in ten WWTPs and the total population of Guangdong and China, the back-estimated usage and estimated emissions per annum can be calculated, and the estimated results are shown in Fig. 5. As shown in Fig. 5(a), DEET, ethylparaben, triclosan, methylparaben and climbazole had high back-estimated usage (> 40 t/y for the whole China), and their huge consumption should be a concern for environmental regulatory bodies and chemical industry. On the basis of the market research data from related reports, the usage of climbazole was estimated to be $345 \mathrm{t} / \mathrm{y}$ in the whole China [47], much higher than this back-estimation (41.3 t/y); while the reported usage of triclosan in the whole China (100 t/y, [48]) was close to this back-estimation $(66.1 \mathrm{t} / \mathrm{y})$. The big difference in estimated usage for climbazole to the previous reported value could be mainly due to different estimation methods. As shown in Fig. 5(b), the estimated emissions of DEET, triclosan, ethylparaben and climbazole in the whole China were more than $30 \mathrm{t} / \mathrm{y}$. On the whole, the total back-estimated usage of $\sum 19$ Biocides was up to $453 \mathrm{t} / \mathrm{y}$ in the whole China, and the total estimated emission of $\sum$ 19Biocides discharged to the receiving environment through effluent and excess sludge was also up to $289 \mathrm{t} / \mathrm{y}$. Such large amount of biocides emissions may pose potential ecological risks to organisms in the environment as indicated in some previous studies $[8,10,11,23]$.

The aquatic ecological risks of the biocides were assessed through the risk quotient (RQ) approach based on their reported predicted no-effect concentration (PNEC) [8] and the measured environmental concentration (MEC) in the receiving rivers. In a word, the RQ values were calculated using the MEC values divided by the PNEC values, and the results of risk assessment are given in Table S26. The criteria of interpreting the RQ values are classified into the following four levels: high risk $(\mathrm{RQ} \geq 1)$, medium risk $(0.1 \leq \mathrm{RQ}<1)$, low risk $(0.01 \leq \mathrm{RQ}<0.1)$ and minimal risk $(\mathrm{RQ}<0.01)$ 
[49]. The results from the present study showed that a majority of biocides in the receiving rivers could pose high risks to aquatic organisms under the "worst case scenario". For all the surface water samples $(\mathrm{n}=18)$, the fractions of high risk were not less than $78 \%$ for clotrimazole, carbendazim and triclosan; among them, the clotrimazole showed high risk in $100 \%$ of the samples. While for all the sediment samples $(\mathrm{n}=17)$, the fractions of high risk for five biocides (climbazole, carbendazim, BIT, triclosan and triclocarban) were not less than 53\%, and two of them (carbendazim and triclocarban) with 100\% high risk fractions. These high risk compounds could cause some adverse effects on aquatic organisms [16-19, 21, 22]. For instance, triclosan and triclocarban can be bioaccumulated in aquatic organisms (e.g., algae, snails and fish) with a log bioaccumulation factor (BAF) of 2.9 3.4 [19, 50, 51]. Contamination of aquatic environments may affect water quality and aquatic food safety, and further pose potential risks to human health. Therefore, in order to minimize the potential ecological risks of the biocides to aquatic organisms even to humans, it is essential to develop a high-efficiency removal technology for biocides in the advanced treatment of WWTPs.

\section{Conclusions}

The results from this study showed that all the target biocides were detected in the sewage and sludge of WWTPs. The dominant biocides were DEET, ethylparaben, methylparaben, triclosan and climbazole for influent, and fluconazole, climbazole and DEET for effluent, and miconazole, clotrimazole, triclosan and triclocarban for excess sludge. Most biocides showed the high aqueous removal rates of more than $70 \%$, with exceptions for thiabendazole, fluconazole and climbazole having mean removal rates $\leq 34 \%$. The technologies of modified A/O, MBR and Carrousel 2000 oxidation ditch showed high removal rates of over $80 \%$ for total biocides, which were attributed to 
biodegradation and adsorption onto sludge. Effluent discharge led to the contamination of biocides in the receiving rivers; consequently some of them could pose high ecological risks to aquatic organisms. Thus, more attention should be paid to this group of biocides, and more efficient treatment technologies should be applied in WWTPs.

\section{Acknowledgements}

The authors would like to acknowledge the financial support from the National Science Foundation of China (NSFC 41473105, U1401235 and 41303077) and National Water Pollution Control Program of China (2014ZX07206-005). Thanks also to Guangzhou Sewage Purification Company for assistance in the sampling campaigns.

\section{References}

[1] EU, The EU Biocides Regulation 528/2012: REGULATION (EU) No 528/2012 OF THE EUROPEAN PARLIAMENT AND OF THE COUNCIL of 22 May 2012 concerning the making available on the market and use of biocidal products, European Parliament 2012. http://www.hse.gov.uk/biocides/eu-bpr/.

[2] Z.F. Chen, G.G. Ying, H.J. Lai, F. Chen, H.C. Su, Y.S. Liu, F.Q. Peng, J.L. Zhao, Determination of biocides in different environmental matrices by use of ultra-high-performance liquid chromatography-tandem mass spectrometry, Anal. Bioanal. Chem. 404 (2012) 3175-3188.

[3] T. Gouin, R. van Egmond, O.R. Price, J.E.N. Hodges, Prioritising chemicals used in personal care products in China for environmental risk assessment: Application of the RAIDAR model, Environ. 
Pollut. 165 (2012) 208-214.

[4] USEPA, Reregistration eligibility decision (RED) for DEET, EPA 738-R-98-010, United States Environmental Protection Agency, Washington, DC, USA, 1998.

[5] Y. Guo, K. Kannan, A Survey of Phthalates and Parabens in Personal Care Products from the United States and Its Implications for Human Exposure, Environ. Sci. Technol. 47 (2013) 14442-14449.

[6] SCCP, Opinion on climbazole (SCCP/1204/08). Scientific Committee on Consumer Products, European Commission, Brussels, Belgium, 2009. http://ec.europa.eu/health/ph_risk/committees/04_sccp/docs/sccp_o_164.pdf

[7] D.S. Wishart, C. Knox, A.C. Guo, D. Cheng, S. Shrivastava, D. Tzur, B. Gautam, M. Hassanali, DrugBank: a knowledgebase for drugs, drug actions and drug targets, Nucleic Acids Res. 36 (2008) D901-D906.

[8] W.R. Liu, J.L. Zhao, Y.S. Liu, Z.F. Chen, Y.Y. Yang, Q.Q. Zhang, G.G. Ying, Biocides in the Yangtze River of China: Spatiotemporal distribution, mass load and risk assessment, Environ. Pollut. 200 (2015) 53-63.

[9] A. Wick, G. Fink, T.A. Ternes, Comparison of electrospray ionization and atmospheric pressure chemical ionization for multi-residue analysis of biocides, UV-filters and benzothiazoles in aqueous matrices and activated sludge by liquid chromatography-tandem mass spectrometry, $\mathrm{J}$. Chromatogr. A 1217 (2010) 2088-2103.

[10] A.J. Al-Rajab, L. Sabourin, D.R. Lapen, E. Topp, Dissipation of triclosan, triclocarban, carbamazepine and naproxen in agricultural soil following surface or sub-surface application of dewatered municipal biosolids, Sci. Total Environ. 512-513 (2015) 480-488. 
[11] X. García-Santiago, A. Franco-Uría, F. Omil, J.M. Lema, Risk assessment of persistent pharmaceuticals in biosolids: Dealing with uncertainty, J. Hazard. Mater. 302 (2016) 72-81.

[12] D.W. Kolpin, E.T. Furlong, M.T. Meyer, E.M. Thurman, S.D. Zaugg, L.B. Barber, H.T. Buxton, Pharmaceuticals, hormones, and other organic wastewater contaminants in US streams, 1999-2000: A national reconnaissance, Environ. Sci. Technol. 36 (2002) 1202-1211.

[13] B.R. Ramaswamy, G. Shanmugam, G. Velu, B. Rengarajan, D.G. Larsson, GC-MS analysis and ecotoxicological risk assessment of triclosan, carbamazepine and parabens in Indian rivers, J. Hazard. Mater. 186 (2011) 1586-1593.

[14] N. Gottschall, E. Topp, C. Metcalfe, M. Edwards, M. Payne, S. Kleywegt, P. Russell, D.R. Lapen, Pharmaceutical and personal care products in groundwater, subsurface drainage, soil, and wheat grain, following a high single application of municipal biosolids to a field, Chemosphere, 87 (2012) 194-203.

[15] J.L. Zhao, Q.Q. Zhang, F. Chen, L. Wang, G.G. Ying, Y.S. Liu, B. Yang, L.J. Zhou, S. Liu, H.C. $\mathrm{Su}, \mathrm{R} . \mathrm{Q}$. Zhang, Evaluation of triclosan and triclocarban at river basin scale using monitoring and modeling tools: implications for controlling of urban domestic sewage discharge, Water Res. 47 (2013) 395-405.

[16] M. Adolfsson-Erici, M. Pettersson, J. Parkkonen, J. Sturve, Triclosan, a commonly used bactericide found in human milk and in the aquatic environment in Sweden, Chemosphere, 46 (2002) 1485-1489.

[17] E. Richter, E. Roller, U. Kunkel, T.A. Ternes, A. Coors, Phytotoxicity of wastewater-born micropollutants - Characterisation of three antimycotics and a cationic surfactant, Environ. Pollut. 208 (2016) 512-522. 
[18] L. Gao, T. Yuan, P. Cheng, Q.F. Bai, C.Q. Zhou, J.J. Ao, W.H. Wang, H.M. Zhang, Effects of triclosan and triclocarban on the growth inhibition, cell viability, genotoxicity and multixenobiotic resistance responses of Tetrahymena thermophila, Chemosphere, 139 (2015) 434-440.

[19] M.A. Coogan, R.E. Edziyie, T.W. La Point, B.J. Venables, Algal bioaccumulation of triclocarban, triclosan, and methyl-triclosan in a North Texas wastewater, treatment plant receiving stream, Chemosphere, 67 (2007) 1911-1918.

[20] J. Corcoran, A. Lange, R.I. Cumming, S.F. Owen, J.S. Ball, C.R. Tyler, M.J. Winter, Bioavailability of the imidazole antifungal agent clotrimazole and its effects on key biotransformation genes in the common carp (Cyprinus carpio), Aquat. Toxicol. 152 (2014) 57-65.

[21] S.A. Raut, R.A. Angus, Triclosan Has Endocrine-Disrupting Effects in Male Western Mosquitofish, Gambusia Affinis, Environ. Toxicol. Chem. 29 (2010) 1287-1291.

[22] C. Taxvig, A.M. Vinggaard, U. Hass, M. Axelstad, S. Metzdorff, C. Nellemann, Endocrine-disrupting properties in vivo of widely used azole fungicides, Int. J. Androl. 31 (2008) 170-176.

[23] Z.F. Chen, G.G. Ying, Y.S. Liu, Q.Q. Zhang, J.L. Zhao, S.S. Liu, J. Chen, F.J. Peng, H.J. Lai, C.G. Pan, Triclosan as a surrogate for household biocides: An investigation into biocides in aquatic environments of a highly urbanized region, Water Res. 58 (2014) 269-279.

[24] F. Heeb, H. Singer, B. Pernet-Coudrier, W.X. Qi, H.J. Liu, P. Longree, B. Muller, M. Berg, Organic Micropollutants in Rivers Downstream of the Megacity Beijing: Sources and Mass Fluxes in a Large-Scale Wastewater Irrigation System, Environ. Sci. Technol. 46 (2012) 8680-8688.

[25] J. Gasperi, D. Geara, C. Lorgeoux, A. Bressy, S. Zedek, V. Rocher, A. El Samrani, G. Chebbo, R. Moilleron, First assessment of triclosan, triclocarban and paraben mass loads at a very large 
regional scale: Case of Paris conurbation (France), Sci. Total Environ. 493 (2014) 854-861.

[26] M. Kahle, I.J. Buerge, A. Hauser, M.D. Muller, T. Poiger, Azole fungicides:Occurrence and fate in wastewater and surface waters, Environ. Sci. Technol. 42 (2008) 7193-7200.

[27] H. Singer, S. Jaus, I. Hanke, A. Luck, J. Hollender, A.C. Alder, Determination of biocides and pesticides by on-line solid phase extraction coupled with mass spectrometry and their behaviour in wastewater and surface water, Environ. Pollut. 158 (2010) 3054-3064.

[28] I. González-Mariño, J.B. Quintana, I. Rodríguez, R. Cela, Evaluation of the occurrence and biodegradation of parabens and halogenated by-products in wastewater by accurate-mass liquid chromatography-quadrupole-time-of-flight-mass spectrometry (LC-QTOF-MS), Water Res. 45 (2011) 6770-6780.

[29] D.C. McAvoy, B. Schatowitz, M. Jacob, A. Hauk, W.S. Eckhoff, Measurement of triclosan in wastewater treatment systems, Environ. Toxicol. Chem. 21 (2002) 1323-1329.

[30] N. Nakada, M. Yasojima, Y. Okayasu, K. Komori, Y. Suzuki, Mass balance analysis of triclosan, diethyltoluamide, crotamiton and carbamazepine in sewage treatment plants, Water Sci. Technol. $61(2010)$ 1739-1747.

[31] X.Z. Peng, Q.X. Huang, K. Zhang, Y.Y. Yu, Z.F. Wang, C.W. Wang, Distribution, behavior and fate of azole antifungals during mechanical, biological, and chemical treatments in sewage treatment plants in China, Sci. Total Environ. 426 (2012) 311-317.

[32] I. González-Mariño, J.B. Quintana, I. Rodríguez, R. Cela, Simultaneous determination of parabens, triclosan and triclocarban in water by liquid chromatography/electrospray ionisation tandem mass spectrometry, Rapid Commun. Mass Sp. 23 (2009) 1756-1766.

[33] L. Clesceri, A. Greenberg, A. Eaton, Standard methods for the examination of water and 
wastewater. 20th ed., Washington, DC: APHA. 2001.

[34] J. Heidler, R.U. Halden, Meta-analysis of mass balances examining chemical fate during wastewater treatment, Environ. Sci. Technol. 42 (2008) 6324-6332.

[35] Z.F. Chen, G.G. Ying, Occurrence, fate and ecological risk of five typical azole fungicides as therapeutic and personal care products in the environment: A review, Environ. Int. 84 (2015) 142-153.

[36] T. Anumol, A. Vijayanandan, M. Park, L. Philip, S.A. Snyder, Occurrence and fate of emerging trace organic chemicals in wastewater plants in Chennai, India, Environ. Int. 92-93 (2016) 33-42.

[37] Y.Y. Yu, Q.X. Huang, Z.F. Wang, K. Zhang, C.M. Tang, J.L. Cui, J.L. Feng, X.Z. Peng, Occurrence and behavior of pharmaceuticals, steroid hormones, and endocrine-disrupting personal care products in wastewater and the recipient river water of the Pearl River Delta, South China, J. Environ. Monit. 13 (2011) 871-878.

[38] U.E. Bollmann, C. Tang, E. Eriksson, K. Jonsson, J. Vollertsen, K. Bester, Biocides in urban wastewater treatment plant influent at dry and wet weather: concentrations, mass flows and possible sources, Water Res. 60 (2014) 64-74.

[39] U.E. Bollmann, J. Vollertsen, J. Carmeliet, K. Bester, Dynamics of biocide emissions from buildings in a suburban stormwater catchment-Concentrations, mass loads and emission processes, Water Res. 56 (2014) 66-76.

[40] S.F. Yang, C.F. Lin, A.Y. Lin, P.K. Hong, Sorption and biodegradation of sulfonamide antibiotics by activated sludge: experimental assessment using batch data obtained under aerobic conditions, Water Res. 45 (2011) 3389-3397.

[41] E. Fernandez-Fontaina, I. Pinho, M. Carballa, F. Omil, J.M. Lema, Biodegradation kinetic 
constants and sorption coefficients of micropollutants in membrane bioreactors, Biodegradation, 24 (2013) 165-177.

[42] USEPA, ECOSAR_v 1.11 software, United States Environmental Protection Agency, Washington, DC, USA, 2012. http://ecosar.software.informer.com/download/

[43] S.F. Yang, C.F. Lin, C.J. Wu, K.K. Ng, A.Y. Lin, P.K. Hong, Fate of sulfonamide antibiotics in contact with activated sludge--sorption and biodegradation, Water Res. 46 (2012) 1301-1308.

[44] W.R. Liu, G.G. Ying, J.L. Zhao, Y.S. Liu, L.X. Hu, L. Yao, Y.Q. Liang, F. Tian, Photodegradation of the azole fungicide climbazole by ultraviolet irradiation under different conditions: Kinetics, mechanism and toxicity evaluation, J. Hazard. Mater. 318 (2016) 794-801.

[45] J. Altmann, D. Rehfeld, K. Träder, A. Sperlich, M. Jekel, Combination of granular activated carbon adsorption and deep-bed filtration as a single advanced wastewater treatment step for organic micropollutant and phosphorus removal, Water Res. 92 (2016) 131-139.

[46] X. Yang, J.L. Sun, W.J. Fu, C. Shang, Y. Li, , Y.W. Chen, W.H. Gan, J.Y. Fang, PPCP degradation by UV/chlorine treatment and its impact on DBP formation potential in real waters, Water Res. 98 (2016) 309-318.

[47] Q.Q. Zhang, G.G. Ying, Z.F. Chen, Y.S. Liu, W.R. Liu, J.L. Zhao, Multimedia fate modeling and risk assessment of a commonly used azole fungicide climbazole at the river basin scale in China, Sci. Total Environ. 520 (2015) 39-48.

[48] Q.Q. Zhang, G.G. Ying, Z.F. Chen, J.L. Zhao, Y.S. Liu, Basin-scale emission and multimedia fate of triclosan in whole China, Environ. Sci. Pollut. R. 22 (2015) 10130-10143. 
[49] M.D. Hernando, M. Mezcua, A.R. Fernandez-Alba, D. Barcelo, Environmental risk assessment of pharmaceutical residues in wastewater effluents, surface waters and sediments. Talanta 69 (2006) 334-342.

[50] M.A. Coogan, T.W. La Point, Snail bioaccumulation of triclocarban, triclosan, and methyltriclosan in a North Texas, USA, stream affected by wastewater treatment plant runoff, Environ. Toxicol. Chem. 27 (2008) 1788-1793.

[51] N.H. Schebb, I. Flores, T. Kurobe, B. Franze, A. Ranganathan, B.D. Hammock, S.J. Teh, Bioconcentration, metabolism and excretion of triclocarban in larval Qurt medaka (Oryzias latipes), Aquat. Toxicol. 105 (2011) 448-454. 
Table 1 The basic information of ten municipal wastewater treatment plants

\begin{tabular}{|c|c|c|c|c|c|c|c|c|c|c|}
\hline \multirow{2}{*}{$\begin{array}{l}\text { Plant } \\
\text { code }\end{array}$} & \multirow[b]{2}{*}{ City } & \multirow[b]{2}{*}{ Process type } & \multirow{2}{*}{$\begin{array}{c}\text { Average } \\
\text { flow }\left(\mathrm{m}^{3} / \mathrm{d}\right)\end{array}$} & \multirow{2}{*}{$\begin{array}{l}\text { Population served } \\
\text { (Ten thousand) }\end{array}$} & \multirow{2}{*}{$\begin{array}{l}\text { Disinfection } \\
\text { method }\end{array}$} & \multirow{2}{*}{$\begin{array}{c}\text { Hydraulic retention } \\
\text { time }(\mathrm{h})\end{array}$} & \multirow{2}{*}{$\begin{array}{c}\mathrm{TSS} \\
(\mathrm{mg} / \mathrm{L})\end{array}$} & \multicolumn{2}{|c|}{ Excess sludge } & \multirow[b]{2}{*}{ Receiving river } \\
\hline & & & & & & & & $\begin{array}{l}\text { Daily production } \\
\text { (t/d, wet weight) }\end{array}$ & $\begin{array}{c}\text { Moisture } \\
\text { content (\%) }\end{array}$ & \\
\hline LB & Dongguan & $\mathrm{A}^{2} / \mathrm{O}$ & 110000 & 30 & UV & 13.5 & 3600 & 34 & 78 & Hanxi River \\
\hline DTS-1 & Guangzhou & $\mathrm{A}^{2} / \mathrm{O}$ & 165000 & 42.8 & $\mathrm{Cl}$ & 12 & 3500 & 45 & 80 & Pearl River \\
\hline DTS-2 & Guangzhou & Reversed $\mathrm{A}^{2} / \mathrm{O}$ & 220000 & 57 & $\mathrm{Cl}$ & 12.5 & 4000 & 60 & 80 & Pearl River \\
\hline HY & Huizhou & Reversed $\mathrm{A}^{2} / \mathrm{O}$ & 76000 & 42.5 & $\mathrm{Cl}$ & 12 & 3000 & 35 & 78 & DanaoRiver \\
\hline MH & Huizhou & Reversed $\mathrm{A}^{2} / \mathrm{O}$ & 88000 & 38 & $\mathrm{UV}+\mathrm{Cl}$ & 12 & 3000 & 30 & 75 & Dongjiang River \\
\hline XT & Guangzhou & Modified $\mathrm{A}^{2} / \mathrm{O}$ & 107000 & 41 & $\mathrm{UV}+\mathrm{Cl}$ & 12.5 & 3500 & 50 & 80 & Dongjiang River \\
\hline LJ & Guangzhou & Modified A/O & 200000 & 54 & $\mathrm{Cl}$ & 10 & 3600 & 48 & 78 & Pearl River \\
\hline JX & Guangzhou & MBR & 100000 & 13 & UV & 9.5 & 6000 & 36 & 76 & Shahe stream \\
\hline HJ & Dongguan & $\begin{array}{l}\text { Carrousel } 2000 \\
\text { Oxidation ditch }\end{array}$ & 47000 & 13 & UV & 11 & 3100 & 15 & 80 & Huangjiang River \\
\hline LD & Guangzhou & UNITANK & 220000 & 39 & $\mathrm{Cl}$ & 13 & 3000 & 47 & 77 & Pearl River \\
\hline
\end{tabular}


Table 2 Pollution loads per capita ( $\mathrm{L}, \mu \mathrm{g} / \mathrm{d} / \mathrm{person})$ of 19 biocides in the influent, effluent and excess sludge of ten WWTPs.

\begin{tabular}{|c|c|c|c|c|c|c|c|c|c|}
\hline \multirow{3}{*}{ Compound } & \multicolumn{3}{|c|}{ Input } & \multicolumn{6}{|c|}{ Output } \\
\hline & \multicolumn{3}{|c|}{$\mathrm{L}_{\text {Influent }}(\mu \mathrm{g} / \mathrm{d} /$ person $)$} & \multicolumn{3}{|c|}{$\mathrm{L}_{\text {Effluent }}(\mu \mathrm{g} / \mathrm{d} /$ person $)$} & \multicolumn{3}{|c|}{$\mathrm{L}_{\text {Excess sludge }}(\mu \mathrm{g} / \mathrm{d} /$ person $)$} \\
\hline & Range & Mean & Median & Range & Mean & Median & Range & Mean & Median \\
\hline Fluconazole & $8.39-60.5$ & 30.3 & 23.7 & $13.1-63.6$ & 34.5 & 28.1 & $0.01-0.12$ & 0.05 & 0.05 \\
\hline Climbazole & $23.6-187$ & 82.6 & 63.5 & $11.0-97.1$ & 42.2 & 39.9 & $0.94-12.7$ & 3.86 & 1.75 \\
\hline Miconazole & $3.09-459$ & 57.5 & 10.9 & $0.17-5.12$ & 1.52 & 1.00 & $4.00-133$ & 20.6 & 8.73 \\
\hline Clotrimazole & $2.40-56.1$ & 20.3 & 15.2 & $0.14-6.18$ & 2.48 & 2.26 & $6.31-62.3$ & 17.9 & 12.8 \\
\hline Thiabendazole & $0.13-0.68$ & 0.38 & 0.36 & $0.10-0.83$ & 0.38 & 0.36 & $0.01-0.03$ & 0.02 & 0.01 \\
\hline Ketoconazole & $1.20-28.2$ & 7.35 & 4.81 & $0.04-1.63$ & 0.53 & 0.14 & $0.20-7.04$ & 2.80 & 2.13 \\
\hline Itraconazole & $0.26-5.80$ & 1.70 & 1.31 & $0.07-0.36$ & 0.17 & 0.12 & $0.10-8.10$ & 3.16 & 2.61 \\
\hline Carbendazim & $7.48-97.1$ & 34.0 & 18.1 & $2.26-21.1$ & 11.1 & 9.36 & $0.05-3.22$ & 0.47 & 0.19 \\
\hline DEET & $71.4-370$ & 151 & 99.1 & $6.56-102$ & 49.5 & 43.7 & $0.01-0.42$ & 0.10 & 0.08 \\
\hline Icaridin & $0.07-4.33$ & 1.08 & 0.54 & $0.00-0.11$ & 0.03 & 0.00 & $0.00-0.00$ & 0.00 & 0.00 \\
\hline BIT & $1.39-109$ & 29.7 & 7.41 & $0.35-8.64$ & 2.02 & 0.72 & $0.13-1.65$ & 0.51 & 0.36 \\
\hline OIT & $0.04-0.62$ & 0.23 & 0.18 & $0.01-0.07$ & 0.02 & 0.01 & $0.00-0.18$ & 0.04 & 0.01 \\
\hline DCOIT & $0.58-21.0$ & 6.86 & 4.24 & $0.19-1.62$ & 0.59 & 0.39 & $0.01-1.84$ & 0.25 & 0.02 \\
\hline Methylparaben & $28.2-303$ & 99.2 & 60.4 & $1.03-7.54$ & 3.52 & 3.19 & $0.54-2.32$ & 1.04 & 0.88 \\
\hline Ethylparaben & $3.23-692$ & 138 & 52.9 & $0.07-1.65$ & 0.71 & 0.74 & $0.02-0.10$ & 0.03 & 0.03 \\
\hline Propylparaben & $10.2-172$ & 57.2 & 29.6 & $0.01-3.03$ & 0.86 & 0.50 & $0.01-0.09$ & 0.03 & 0.02 \\
\hline Butylparaben & $0.03-31.4$ & 4.16 & 1.02 & $0.02-0.20$ & 0.07 & 0.05 & $0.00-0.01$ & 0.01 & 0.01 \\
\hline Triclosan & $24.7-350$ & 132 & 93.1 & $3.46-92.1$ & 23.0 & 11.4 & $8.24-49.4$ & 19.3 & 12.6 \\
\hline Triclocarban & $19.1-112$ & 54.3 & 40.1 & $2.45-29.6$ & 13.6 & 13.5 & $23.8-180$ & 51.1 & 32.8 \\
\hline$\sum$ 19Biocides & $272-2760$ & 907 & 629 & 63.1-366 & 187 & 166 & 56.8-449 & 121 & 83.4 \\
\hline
\end{tabular}




\section{Figure captions}

Fig. 1 The concentration levels of the five classes of biocides in the influent (a), effluent (b) and excess sludge (c) of ten WWTPs.

Fig. 2 Aqueous removal rates for 19 biocides (a) and the five classes of biocides (b) in ten WWTPs.

Fig. 3 Mass balance analysis (mass fractions) for 19 biocides between input and output in ten WWTPs.

Fig. 4 Mass fractions (a) and mass loads (b) of 19 biocides as the forms of dissolved or adsorbed phases in the biochemical stages. Mean values from ten WWTPs are presented.

Fig. 5 Back-estimated usage (a) and estimated emissions (b) per annum of 19 biocides in Guangdong province and China. 
Fig. 1
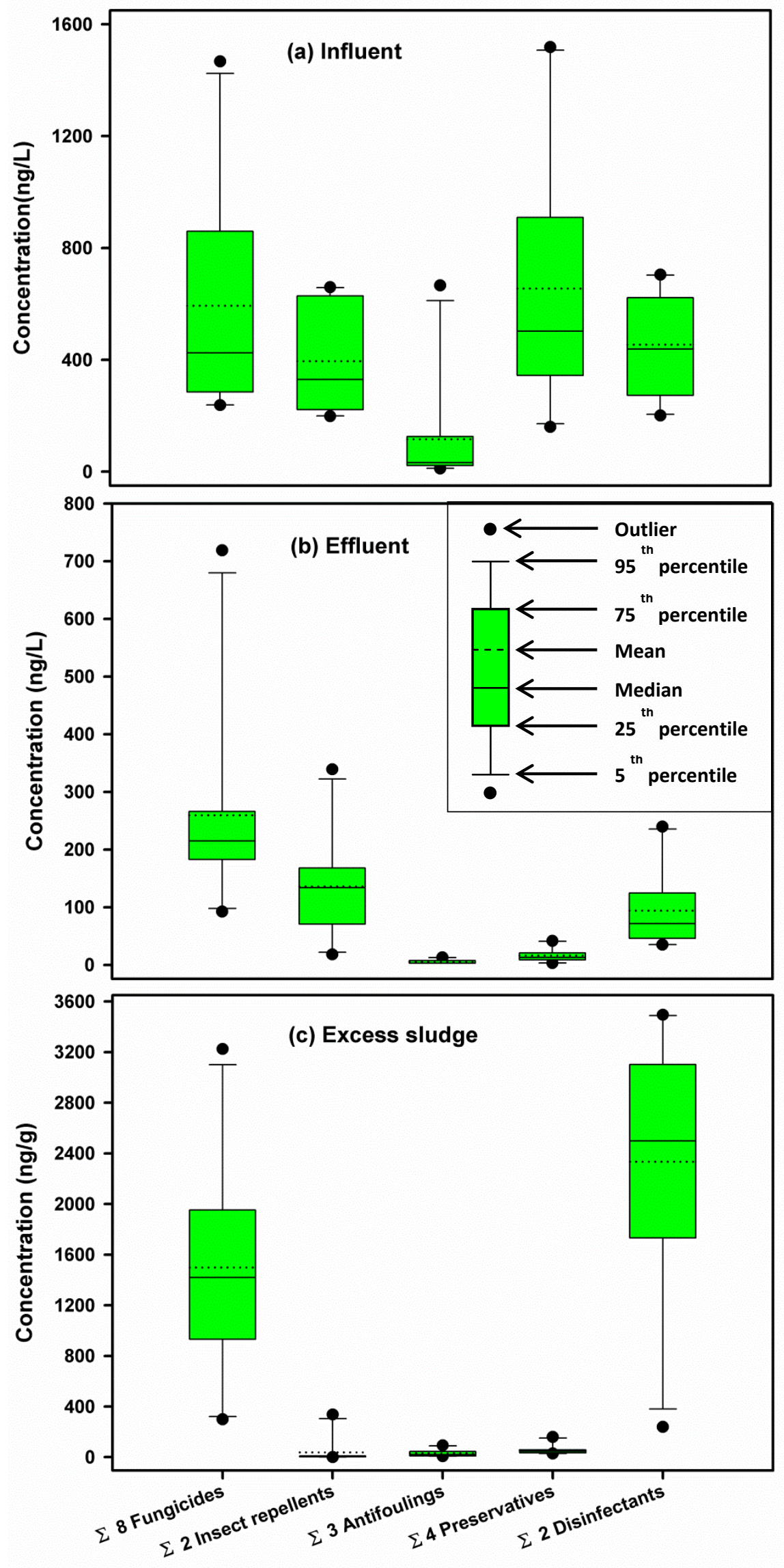
Fig. 2

Removal rate (\%)

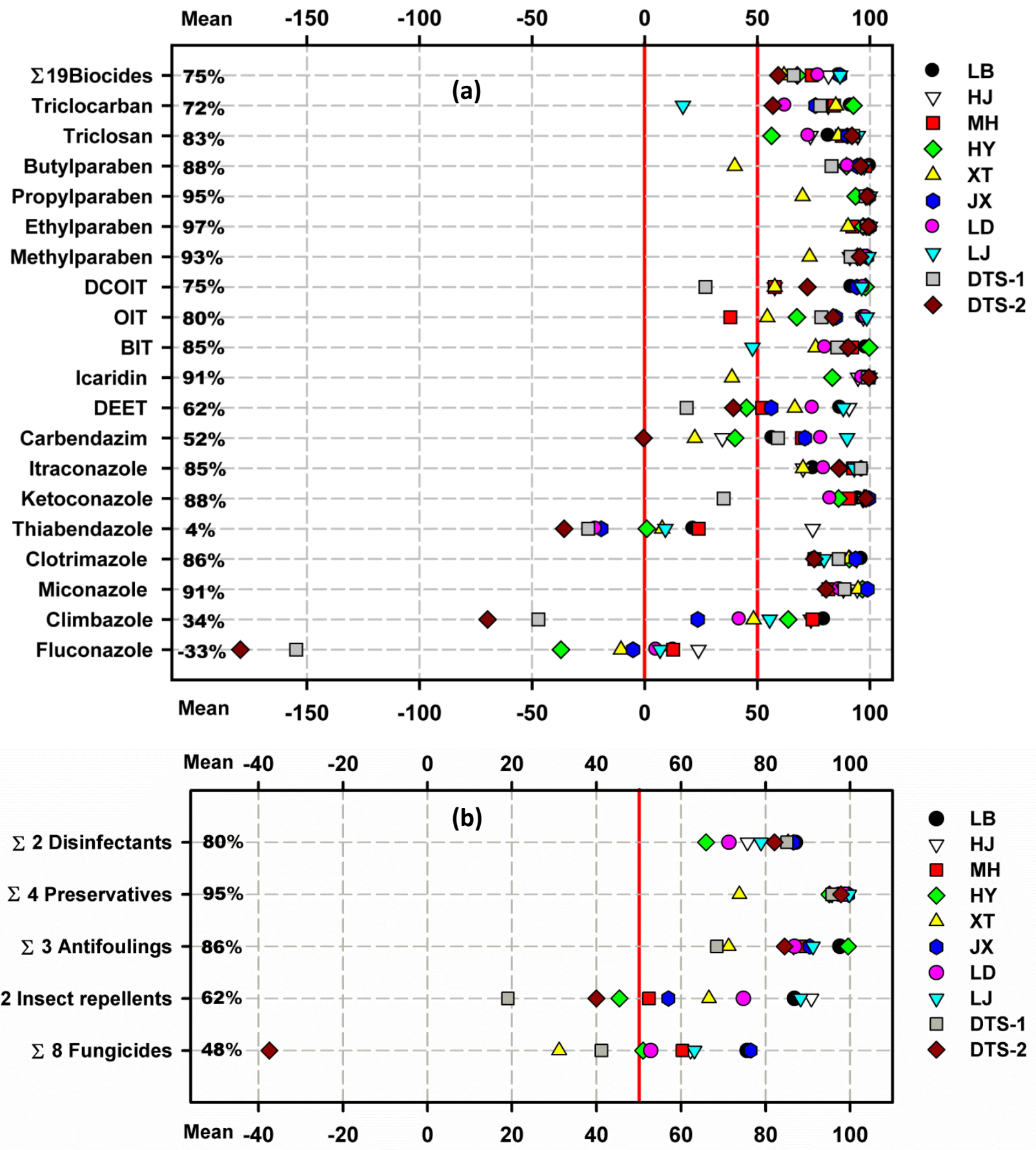


Fig. 3
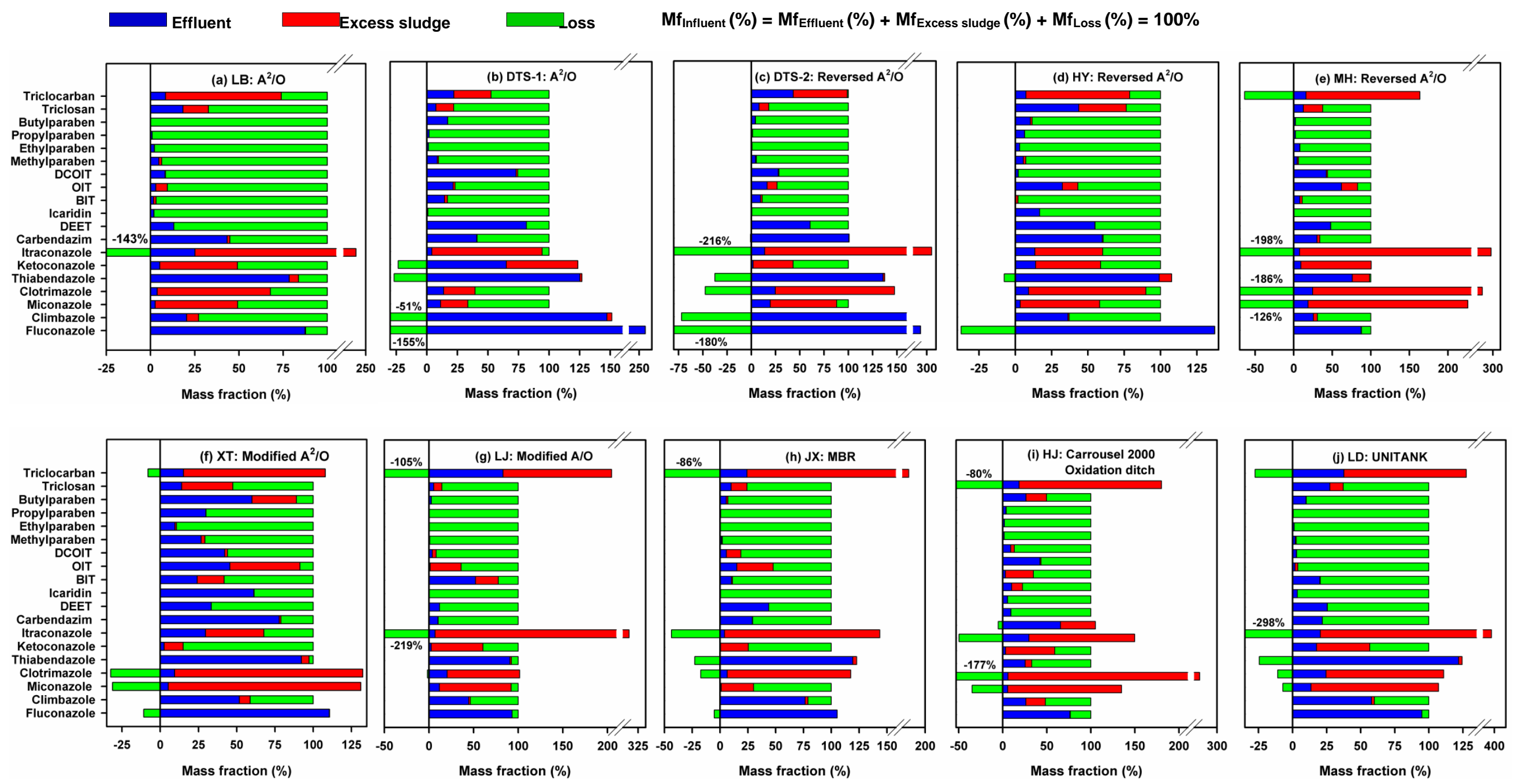
Fig. 4
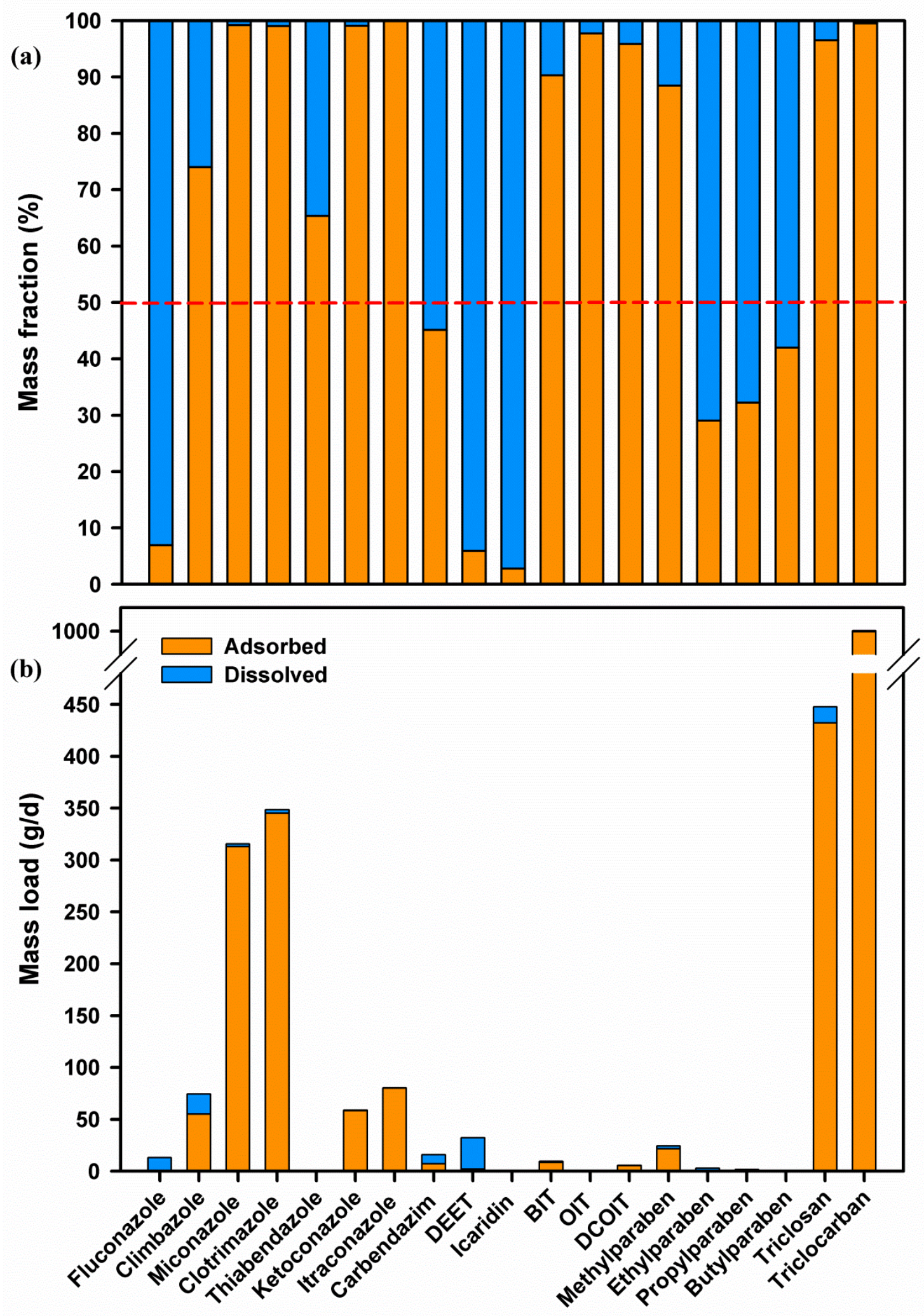
Fig. 5
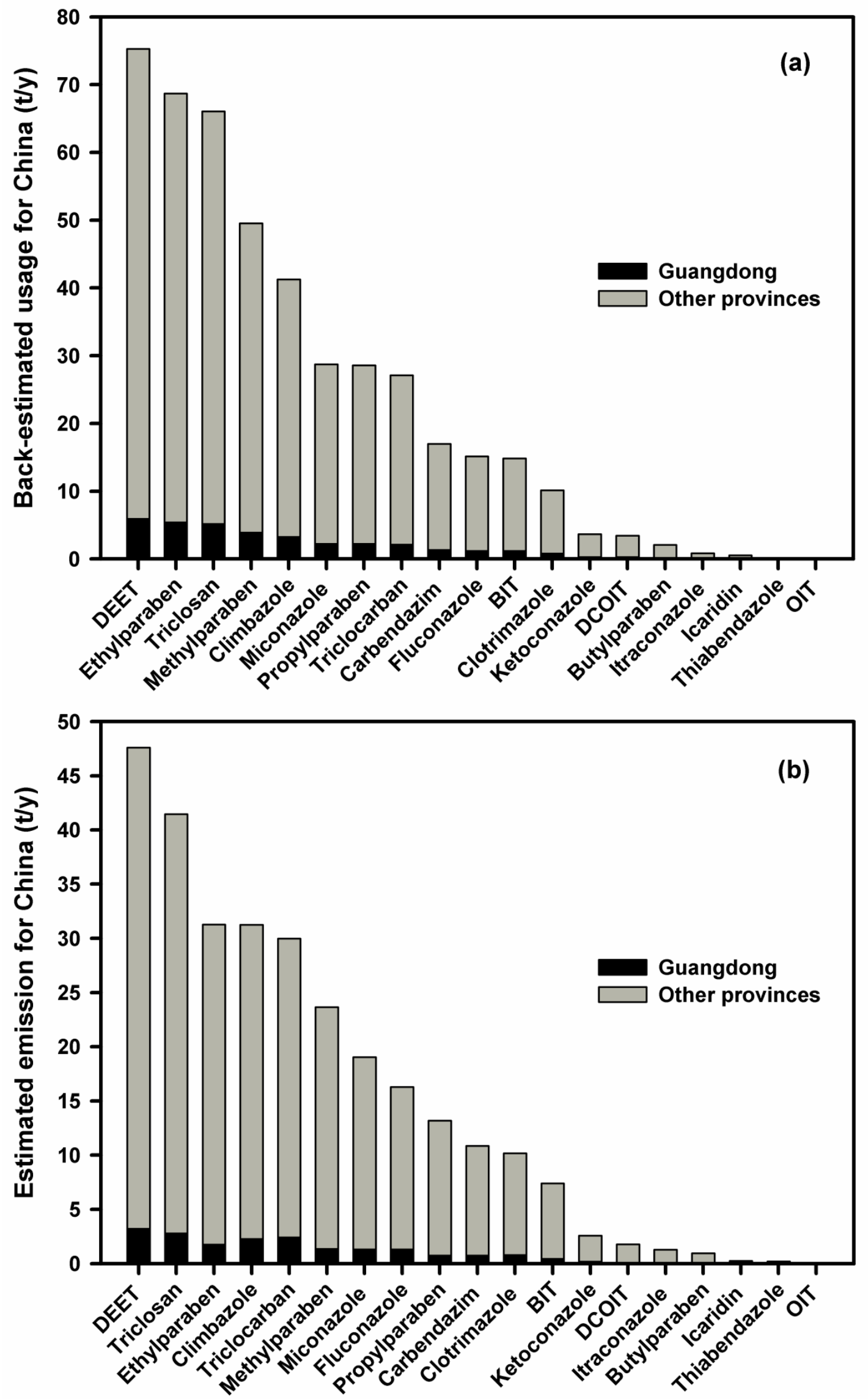